\title{
Contribution of Clinical Simulation in Neonatal Resuscitation Training at the University Teaching Hospital (UTH) of Bogodogo in Ouagadougou, Burkina Faso
}

\author{
A. Ouattara ${ }^{1 *}$, Y. A. Sawagogo ${ }^{1}$, S. Kiemtoré1, I. Ouédraogo 2 , F. D. Traoré/Millogo', \\ C. M. R. Ouédraogo ${ }^{1}$, A. Ouédraogo ${ }^{1}$, B. Thieba/Bonané ${ }^{1}$
}

${ }^{1}$ Department of Gynecology, Obstetrics of the UFR/SDS of the Joseph KI ZERBO University, Ouagadougou, Burkina Faso

${ }^{2}$ Department of Gynecology, Obstetrics of the UFR/SS of the Ouahigouya University, Ouahigouya, Burkina Faso

Email: *ouattzangaadama@yahoo.fr

How to cite this paper: Ouattara, A., Sawagogo, Y.A., Kiemtoré, S., Ouédraogo, I., Traoré/Millogo, F.D., Ouédraogo, C.M.R., Ouédraogo, A. and Thieba/Bonané, B. (2021) Contribution of Clinical Simulation in Neonatal Resuscitation Training at the University Teaching Hospital (UTH) of Bogodogo in Ouagadougou, Burkina Faso. Open Journal of Obstetrics and Gynecology, 11, 53-62. https://doi.org/10.4236/ojog.2021.111007

Received: November 1, 2020

Accepted: January 26, 2021

Published: January 29, 2021

Copyright $\odot 2021$ by author(s) and Scientific Research Publishing Inc. This work is licensed under the Creative Commons Attribution International License (CC BY 4.0).

http://creativecommons.org/licenses/by/4.0/ (c) (i) Open Access

\begin{abstract}
Objective: To study the place of simulation in the learning of newborn resuscitation among seventh year medical students at the University Hospital of Bogodogo in Ouagadougou, Burkina Faso. Material and Method: Our study took place in the obstetrical gynaecology department of the University Hospital Centre of Bogodogo (UTH-B) from 15 December 2018 to 15 March 2019. We randomly selected two groups of students, with no stimulation. We recorded a theoretical questionnaire to all students at the beginning and then carried out two stimulation sessions at 1 month intervals in the competence laboratory of the National School of Public Health. Then we evaluated the theoretical and practical progress of the students over time. We analyzed our data through the Epi info software in version 3.5.1. Results: The two simulation sessions positively influenced the theoretical knowledge of neonatal intensive care for 7 th year students $(\mathrm{p}=0.0391)$. Neonatal resuscitation management by students is better from one simulation session to another with a statistically significant difference $(p=0.0001)$. Conclusion: Our study of 7 th grade students showed the importance of this tool in their practical training at the University Hospital of Bogodogo. Advocacy must be organized for its acquisition in the university hospitals of Burkina Faso.
\end{abstract}

\section{Keywords}

Simulation, Students in Medicine, UTH, Bogodogo, Ouagadougou 


\section{Introduction: Statement of the Problem}

Simulation-based medical training provides a learner-centred environment that allows the trainer to give the learner his or her full attention. Simulation is an experiential learning model, where one can work on the "error" since it is allowed on the patient dummy. Using clinical situations in the field effectively develops skills in understanding situations and clinical reasoning [1]-[6].

It allows errors to evolve, without fear of harm. During a simulation session, the learner simultaneously constructs and deconstructs his knowledge and tests his effectiveness. This learning style seems to correspond to our needs. It is appreciated by students and trainers because it provides a concrete response to the difficulties encountered daily by health professionals. A transition to the simulator allows everyone to quickly identify their limits and shortcomings [7] [8] [9]. In addition, learning by high-fidelity clinical simulation also makes it possible to meet the "never the first time on the patient" rule and thus strengthen patient safety [10]-[20].

During the formative years at midwifery and medical schools, technical knowledge and skills are taught in order to achieve neonatal resuscitation. Also, for ethical reasons, neonatal resuscitation is performed directly by the gynecologist or midwife waiting for the latter, with students rarely having the opportunity to be at the forefront of this neonatal rescue session.

In the University Hospitals of Ouagadougou, neonatal resuscitation training has just been revitalized thanks to the support of certain non-governmental organizations (NGOs) that have funded and equipped competence laboratories for the benefit of medical students and midwives, through the establishment of a simulation centre for clinical situations encountered during internships. However, in practice, this situation is very new and the student (midwife and medicine) has not yet made good use of this training tool.

Our research work aims to describe the importance of simulation in the learning process of resuscitation technique among student trainees at the University Hospital of Bogodogo in Ouagadougou, Burkina Faso.

\section{Materials and Method}

\subsection{Scope of the Study}

Our study took place in the obstetrical gynaecology department of the University Hospital Centre of Bogodogo (UTH-B). This service provides hospital supervision for medical and pharmaceutical students in the Health Science Training and Research Unit (HSTR) and students at the National School of Public Health (NSPH) and certain private schools (midwife and nurses). This department has signed an agreement with the NSPH for the use of its competence laboratory.

The Birth Box provides supervision of women in labour, their delivery and care and resuscitation of the newborn. It contains 3 delivery tables and a waiting room with 3 beds. In this birth room, we can see a room dedicated to the resuscitation of the newborn. A resuscitation table for the functional newborn of the 
newborn is present. The Operating Room, with two rooms where emergency caesarean sections are performed pending the opening of the 3rd operating room in the maternity ward.

\subsection{Type and Period of Study}

This was a cross-sectional cohort study with a descriptive and analytical focus. It was conducted over a 3-month period from December 15, 2018 to March 15, 2019.

\subsection{Study Population}

The study concerned all midwife and medicine students affected and present in the obstetrical gynaecology department of the University Hospital of Bogodogo during the period of the study. We were interested in end-of-cycle students, i.e. the 7 th year for medicine and for midwives, the 3 rd year.

Included in our study were all students who met the following criteria:

- Be a 7th year medical student or a 3rd year midwife.

- Be regularly enrolled in a Higher Education Institute in the city of Ouagadougou.

- To be assigned to the gynaecology department of the University Teaching Hospital of Bogodogo as part of the practical training.

- Be actually present at the internship site during the survey period.

All students who met the following criteria were excluded in our study.

- Refusing to give to participate in the study.

- Be absent from the internship site at the time of the survey.

\subsection{Sampling}

We decided to conduct the survey of regularly assigned medical students and assigned midwife students. Unfortunately, the study period coincided with a period of noninternship for midwife students. We decided to study with students in 7 th year of medical school, that is 48 students.

For the purposes of the survey, we divided our students into 2 groups of 24 . The choice of the group was made by simple random draw without discount during an early morning staff session in front of all the agents of the service on the basis of a list sent by the internship department of Ouaga University 1 Professor Joseph Ki Zerbo. The distribution by group was done according to the following model:

- Group 1 corresponds to students who have received stimulation sessions in the NSPH competence laboratory.

- Group 2 corresponds to students who have not received a stimulation session.

\subsection{Tools and Procedure for Data Collection}

An anonymous theoretical questionnaire was distributed to all 7 th year students at a meeting on 15 December 2018, in order to assess their theoretical knowledge 
before the simulation sessions. This questionnaire was composed of a theoretical and a clinical part.

Students in Group 1 then participated in two simulation sessions on neonatal resuscitation approximately one month apart in the ENSP laboratories on December 20, 2018 and January 20, 2019. During each session, pairs were drawn by lot, each playing alternately once the role of the helper and once the role of the resuscitator doctor. Only the management by the intensive care physician was evaluated in the study, thanks to a criterated grid showing the different times and requirements of neonatal intensive care.

Different scenarios have been pre-established in advance. The two members of each pair intervened on a different scenario.

The clinical simulation exercise lasted about 10 minutes per person, the time allowed for debriefing was 45 minutes.

After the simulation sessions of group 1 , the correction of questionnaire $n^{\circ} 1$ was sent to all students.

One month after the simulation sessions, i.e. on 15 February 2019, a second theoretical questionnaire was distributed, using the same format as the first one, but with different questions. The evolution of theoretical and practical knowledge in both groups was noted.

\subsection{Data Management and Processing}

The data were entered on a laptop computer and analyzed with the Epi info software in version 3.5.1. The statistical analysis was done with parametric tests (the $\mathrm{Z}$ and $\mathrm{t}$ student distribution for the mean and proportions) and non-parametric tests (the chi square test and the Fischer test for the numbers).

\subsection{Ethical Considerations}

All students were informed of the purpose of the study and their consent was obtained. We have ensured the confidentiality of all data collected and the anonymity of study participants. This data will only be used for medical purposes.

\section{Results}

\subsection{Theoretical Evaluation}

\subsubsection{The 1st Questionnaire}

An anonymous theoretical questionnaire was distributed to all 7th year students to assess their theoretical knowledge before the simulation sessions. The results of the evaluation of the 1st questionnaire according to the group and the previous elements of the students were presented in Table 1.

The average obtained on this 1st questionnaire by all students in the 48 th year students is $9.28+/-2.81$ out of 20 . Repetition of repetitions, participation in neonatal resuscitation on the training grounds, or participation in an additional simulation session did not impact the averages obtained in the first questionnaire. 
Table 1. Results obtained by students on the 1st theoretical questionnaire according to the different characteristics.

\begin{tabular}{|c|c|c|c|c|c|c|}
\hline & \multicolumn{2}{|c|}{$\begin{array}{c}\text { Repetition } \\
\text { of class }\end{array}$} & \multicolumn{2}{|c|}{$\begin{array}{c}\text { Previous } \\
\text { participation } \\
\text { in neonatal resuscitation }\end{array}$} & \multicolumn{2}{|c|}{$\begin{array}{l}\text { Previous internship in } \\
\text { the multipurpose } \\
\text { resuscitation service }\end{array}$} \\
\hline & yes & no & yes & no & yes & no \\
\hline Number & 8 & 40 & 26 & 22 & 10 & 38 \\
\hline $\begin{array}{c}\text { average } \\
+/-\sigma\end{array}$ & $9.01+/-3.32$ & $8.95+/-2.50$ & $9.15+/-2.41$ & $8.73+/-2.61$ & $10+/-3.74$ & $9.84+/-0.32$ \\
\hline $\begin{array}{l}\text { Min-Max } \\
\text { of } 20\end{array}$ & $6-12$ & $6-15$ & $6-16$ & $7-11$ & $9-17$ & $6-11$ \\
\hline $\begin{array}{c}\text { Median of } \\
20\end{array}$ & 9 & 8 & 9 & 11 & 12 & 9 \\
\hline $\mathrm{p}$ & \multicolumn{2}{|c|}{$\mathrm{p}=0.565$} & \multicolumn{2}{|c|}{$\mathrm{p}=0.292$} & \multicolumn{2}{|c|}{$\mathrm{p}=0.881$} \\
\hline
\end{tabular}

\subsubsection{Comparison of Results to Theoretical Questionnaires}

\section{1) Overall comparison}

We distributed a 2nd theoretical questionnaire to all students after the simulation sessions of group 1.

The results obtained by students on the 1st and 2nd questionnaires according to their home group (simulation or not) have been presented in Table 2. The average obtained by the students in the 2 nd questionnaire is $9.76+/-2.61$. The averages of the two groups were homogeneous before the simulation. The difference between the average of the scores obtained on the 2nd questionnaire by the simulation group and the group without simulation was statistically significant.

In addition, the theoretical questionnaire was composed of a theoretical and a clinical part. We compared the results obtained by the students in each part.

\section{2) Comparison on the theoretical part}

For the theoretical part of the questionnaires, the results obtained by the students were consistent regardless of the home group and whether or not they participated in the simulation sessions. These results have been presented in Table 3.

\section{3) Clinical comparison}

For the clinical part, during the 2nd questionnaire, the difference in means between the simulation group and the other group was statistically significant ( $\mathrm{p}$ $=0.0391)$. These results have been presented in Table 4 .

\subsection{Simulation Sessions}

The evolution of the results obtained by Group 1 students in the two simulation sessions was presented in Table 5 . The average score for the first simulation session was $3.15+/-4.66$ out of 20 and the average score for the second simulation session was $8.36+/-2.86$ out of 20 . The average difference was 5.21. According to the T-Student test, the difference was significant. 
Table 2. Comparison of the results obtained by students on the 1st and 2nd questionnaires according to their home group (simulation or not).

\begin{tabular}{|c|c|c|c|c|}
\hline \multirow{2}{*}{ Groups } & \multicolumn{2}{|c|}{$1^{\text {st }}$ questionnaire } & \multicolumn{2}{|c|}{$2^{\text {nd }}$ questionnaire } \\
\hline & G1 & G2 & G1 & G2 \\
\hline average $+/-\sigma$ & $9.22+/-2.78$ & $9.35+/-2.84$ & $13.33+/-1.56$ & $8.69+/-2.69$ \\
\hline Min-Max (of 20) & $6-12$ & $6-17$ & $9-19$ & $4-12$ \\
\hline Median of 20 & 10 & 9 & 12 & 8 \\
\hline $\mathrm{p}$ & \multicolumn{2}{|c|}{$\mathrm{p}=0.7831$} & \multicolumn{2}{|c|}{$\mathrm{p}=0.0098$} \\
\hline
\end{tabular}

Table 3. Comparison of the results of the theoretical part obtained by students on the 1st and 2nd questionnaires according to their home group (simulation or not).

\begin{tabular}{ccccc}
\hline \multirow{2}{*}{ Groups } & \multicolumn{2}{c}{$1^{\text {st }}$ questionnaire } & \multicolumn{2}{c}{$2^{\text {nd }}$ questionnaire } \\
\cline { 2 - 5 } & \multicolumn{1}{c}{ G1 } & G2 & G1 & G2 \\
\hline average +/- $\sigma$ & $4.05+/-1.12$ & $4.19+/-1.23$ & $5.17+/-1.64$ & $4.23+/-1.01$ \\
Min-Max (of 20) & $2-6$ & $2-6.5$ & $2-8$ & $2-6$ \\
Median of 20 & 4.35 & 4.01 & 4.55 & 4.00 \\
$\mathrm{p}$ & \multicolumn{2}{c}{$\mathrm{p}=0.2835$} & \multicolumn{2}{c}{$\mathrm{p}=0.0969$} \\
\hline
\end{tabular}

Table 4. Comparison of the results of the clinical part obtained by students on the 1st and 2nd questionnaires according to their home group (simulation or not).

\begin{tabular}{ccccc}
\hline \multirow{2}{*}{ Groups } & \multicolumn{2}{c}{$1^{\text {st }}$ questionnaire } & \multicolumn{2}{c}{$2^{\text {nd }}$ questionnaire } \\
\cline { 2 - 5 } & G1 & G2 & G1 & G2 \\
\hline average +/- $\sigma$ & $5.17+/-1.66$ & $5.16+/-1.61$ & $8.16+/-0.008$ & $4.46+/-1.68$ \\
Min-Max (of 20) & $3-9$ & $4-9$ & $6-10$ & $0-8$ \\
Median of 20 & 6 & 6 & 8.5 & 6 \\
p & & $\mathrm{p}=0.4392$ & \multicolumn{2}{c}{$\mathrm{p}=0.0391$} \\
\hline
\end{tabular}

Table 5. Comparison of the results obtained by Group 1 students in the two simulation sessions.

\begin{tabular}{ccc}
\hline & $1^{\text {st }}$ session & $2^{\text {nd }}$ session \\
\hline average $+/-\sigma$ (of 20) & $3.15+/-4.66$ & $8.36+/-2.86$ \\
Min-Max & $0-8.85$ & $1.4-14.70$ \\
Median & 5.24 & 10.58 \\
Average gap & & 5.21 \\
$\mathrm{p}$ & & $(\mathrm{p}=0.0001)$ \\
\hline
\end{tabular}

\section{Discussion}

\subsection{Limitations/Strength of the Study}

\section{Limitations}

One of the main limitations was that students were aware that they were participating in a study on neonatal resuscitation, even though they had been asked 
not to revise either the questionnaire or the simulation sessions. As a result, we were able to unconsciously induce a positive effect on student perception of the clinical simulation. Similarly, the fact that we are their mentor may have influenced the content of the survey.

The last limitation could come from the fact that the equipment used only allows low-fidelity stimulation. If we had used high-fidelity equipment, it would have had the advantage of creating more excitement among students.

\section{$\checkmark$ Strength}

This is the first study in Burkina Faso, in which the theoretical results of students who have benefited from sessions or not, were compared in order to observe whether there is a progression in neonatal intensive care learning via high-fidelity clinical simulation sessions. Indeed, although there has already been work on the value of clinical simulation in the training of students in neonatal resuscitation, it was either the students' perception of this learning method or the impact on their early career practice, which is subjective.

The criteria grid allowed a detailed evaluation of all the actions implemented by each student. Two or three teachers from the school were present at each session. I also attended all the simulation sessions. The scoring was done by comparing everyone's observations.

\subsection{Theoretical Evaluation}

\subsubsection{Does Simulation Influence Theoretical Knowledge?}

Our main objective was to show that two simulation sessions influence the theoretical knowledge of neonatal intensive care for 7 th year students. In the analysis of the results, the difference was statistically significant $(p=0.0391)$.

The two simulation sessions therefore had a positive influence on the theoretical knowledge of neonatal intensive care for 7 th year students.

J. BERTON, director of the Angers simulation centre, made this observation: "According to the learning technique, memorization is very different. On average, we retain $10 \%$ of what we learn from reading, and $75 \%$ of what is learned from practice" [16].

The results obtained are in line with this, since the students who conducted the two simulation sessions between the two questionnaires obtained a higher score on the 2nd theoretical questionnaire.

Our questionnaire was divided into two parts: a pure theoretical part with questions such as MCQs, and a clinical part where we asked the students to perform the acts and to order them. Both simulation sessions positively influenced the results of both parts, but a higher progression was observed for the clinical part. We can therefore say that clinical simulation makes it possible to review theoretical knowledge on neonatal resuscitation, but above all it makes it possible to appropriate the management algorithm.

\subsubsection{Explanation of Theoretical Results}

The average obtained by students on the first questionnaire is less than 10/20. 
One of the 2nd questionnaires by the group without simulation is also less than $10 / 20$. Only the simulation group obtained an average of more than $10 / 20$ in the 2nd questionnaire.

In order to analyze these results, it is necessary to have an overview of student training in neonatal resuscitation during medical studies at the University of Ouaga 1, Professor Joseph KI ZERBO. In 5th year, they attend a theoretical course and a practical session concerning the reception of the newborn in a context where it only requires the aspiration of the VAS. But in reality, there is no specific chapter dedicated to newborn resuscitation especially in the context of the LMD system which reduces theoretical teaching to the benefit of the student's personal work. Consultation with the Department of Pediatrics would make it possible to find solutions to this deficiency.

We wanted to compare the results obtained by the students on the 1st questionnaire according to different parameters: repetition, participation in neonatal resuscitation during their internship and/or participation in a major resuscitation internship. None of these parameters influenced the results of the theoretical questionnaire. For repetition and participation in a major intensive care unit, the reason is probably lack of power.

\subsection{Simulation Sessions}

Neonatal resuscitation management by students is better from one simulation session to another since the average difference is 5.21 points. This difference was statistically significant ( $p=0.0001$ ). Students' knowledge of the algorithm for managing neonatal resuscitation is therefore better from one simulation session to another.

The students who were part of our study population are currently at the end of the 7th year bis, i.e. thesis year. They were evaluated on the management of neonatal resuscitation at the end of the training course through a simulation session. The average obtained by all students confirms the significant margin for improvement mentioned above.

\section{Conclusions}

The doctor is often in the first line to start this resuscitation. Its learning is therefore not suitable for teaching in the field. Clinical simulation seems to be a way to progress in the management of critical incidents in the birth room.

A literature review was conducted by the Best Evidence for Medical Education (BEME) group to answer the question: "What factors contribute to quality learning in simulation-based teaching?” [21] [22] [23], the important elements are:

- Debriefing

- Repeated practice

- The integration of professional training into the curriculum.

In view of these criteria, learning neonatal resuscitation in the obstetrical gy- 
naecology department of the University Hospital of Bogodogo must be a reality.

We hypothesized that simulation was recognized by the majority of FHTs as an essential tool for acquiring a better professional posture: self-confidence, teamwork, gestural dexterity, stress management. By validating it, our study therefore reinforces the data in the literature.

Neonatal resuscitation is a frequent situation in Burkina Faso, affecting only $28 \%$ of births in Burkina Faso. The results of this study will be used to make recommendations for the generalization of this pedagogical method at the national level.

\section{Conflicts of Interest}

The authors declare no conflicts of interest regarding the publication of this paper.

\section{References}

[1] Francoual, C., Bouillié, J. and Parat-Lesbros, S. (2008) Pédiatrie en maternité. Medecine-Science Flammarion, Paris, 688 p.

[2] Fayol, L., Andres, V. and Siméoni, U. (2011) Réanimation en salle de naissance: Recommandations 2010. Vol. 18, Hors série No. 1, 264. https://doi.org/10.1016/S0929-693X(11)70994-0

[3] Godde, F. and Norbert, K. (2012) Réanimation du nouveau-né en salle de naissance. Support pédagogique. Sauramps medical.montpellier, $130 \mathrm{p}$.

[4] Code de la santé publique-Article R4127-318.

[5] Karaguinsky, C. (2012) Les étudiants sages-femmes sont-ils suffisamment préparés à la réanimation néonatale durant leurs études? Zoom sur l'enseignement dispensé dans les écoles françaises, Mémoire de sage-femme. Clermont-Ferrand, $76 \mathrm{p}$.

[6] Bouin, T. (2012) L'utilisation de la simulation médicale dans la formation des étudiants sages-femmes. No. 95.

[7] Coyer, C. (2013) la simulation haute fidélité dans la formation des étudiants sagefemme la réanimation néonatale. Mémoire de sage-femme. Angers, $70 \mathrm{p}$.

[8] Granry, J.C. and Moll, M.C. (2012) Rapport de la Haute Autorité de Santé. État de l'art (national et international) en matière de pratiques de simulation dans le domaine de la santé. Dans le cadre du développement professionnel continu (DPC) et de la prévention des risques associés aux soins. http://www.has-sante.fr

[9] Haute Autorité de Santé (France) (2012) Guide de Bonnes Pratiques en matière de simulation en santé.

[10] Chiniara, G. (2007) Simulation médicale pour acquisition des compétences en anesthésie. In: Société française d'anesthésie et de réanimation, Ed., Congrès national d anesthésie et de réanimation 2007, Conférences d'actualisation, SFAR, Paris, 41-49.

[11] Ziv, A., Wolpe, P.R., Small, S.D. and Glick, S. (2003) Simulation-Based Medical Education: An Ethical Imperative. Academic Medicine, 78, 783-788. https://doi.org/10.1097/00001888-200308000-00006

[12] Twigg, S.J., McCormick, B. and Cook, T.M. (2003) Randomized Evaluation of the Performance of Single-Use Laryngoscopes in Simulated Easy and Difficult Intubation. British Journal of Anaesthesia, 90, 8-13. 
https://doi.org/10.1093/bja/aeg001

[13] Committee on Quality of Health Care in America (2000) To Err Is Human. In: Kohn, L.T., Corrigan, J.M. and Donaldson, M.S., Eds., Building a Safer Health System, Institute Of Medicine, National Academy Press, Washington DC, 312 p.

[14] Cook, D.A., Hatala, R., Brydges, R., Zendejas, B., Szostek, J.H., Wang, A.T., Erwin, P.J. and Hamstra, S.J. (2011) Technology-Enhanced Simulation for Health Professions Education: A Systematic Review and Meta-Analysis. JAMA, 306, 978-988. https://doi.org/10.1001/jama.2011.1234

[15] Jouquan, J. (2002) L'évaluation des apprentissages des étudiants en formation médicale initiale. Pédagogie Médicale, 3, 38-52.

https://doi.org/10.1051/pmed:2002006

[16] Centre Hospitalier Régional d’Angers (2014) Une journée pour découvrir la formation en santé par la simulation à Angers.

[17] Fischer, L. (2013) Imulation médicale: Ses apports dans l'enseignement de la réanimation néonatale au étudiants sages-femmes. Nancy.

[18] Faury, M.-N. (2011) Didactique professionnelle-Simulation et réanimation néonatale. Rouen, $146 \mathrm{p}$.

[19] Guedichi, H. (2013) Evaluation de l'intérèt pédagogique per u par les étudiants l'introduction des simulations physiques sur mannequin haute fidélité et virtuelle (jeu sérieux) dans le curriculum des études de sage-femme: L'exemple de l'hémorragie du post partum. Dijon, $68 \mathrm{p}$.

[20] Ismail, M. (2012) Embolie de liquide amniotique: Connaissances des sages-femmes et intérêt de la simulation haute-fidélité dans l'apprentissage de la prise en charge de l'embolie amniotique. http://dumas.ccsd.cnrs.fr/dumas-00724906

[21] Marillier, J. (2011) Formation des étudiantes sages-femmes sur la prise en charge de la détresse respiratoire en salle de naissances. Université Paris Descartes, Paris, 75 p.

[22] Boet, S., Granry, J.-C. and Savoldelli, G. (2016) La simulation en santé: De la théorie la pratique. Springer, Berlin, $442 \mathrm{p}$.

[23] Barry Issenberg, S., Mcgaghie, W.C., Petrusa, E.R., Lee Gordon, D. and Scalese, R.J. (2005) Features and Uses of High-Fidelity Medical Simulations That Lead to Effective Learning: A BEME Systematic Review. Medical Teacher, 27, 10-28. https://doi.org/10.1080/01421590500046924 